\title{
Longitudinal Study of Posttraumatic Stress Symptoms in Adults and Adolescents after Osh Events in 2010
}

\author{
Elena Molchanova, American University in Central Asia; \\ Tatiana Galako, Kyrgyz State Medical Academy \\ Bishkek, Kyrgyz Republic
}

\section{Introduction}

The Kyrgyz Republic (or Kyrgyzstan) is a mountainous country in post-Soviet Central Asia with a population of approximately five million people living on the territory of 200 thousand square $\mathrm{km}$. It borders with Kazakhstan, Uzbekistan, Tajikistan, and China. The ethnic composition of the country is very complex and includes major groups such as ethnic Kyrgyz (67\%), ethnic Uzbeks (14\%), ethnic Russians (10\%) and more than eighty other ethnicities. Landlocked and with little local industry and only a few natural resources (including gold, hydropower, and cotton) Kyrgyzstan is economically vulnerable. Due to the unique geographic location, the Kyrgyz Republic is a subject to numerous natural disasters. Mudflows, landslides, and earthquakes are considered to be typical emergencies in $K R$, and the Kyrgyz Ministry of Emergency Situations (KMES) has developed the detailed algorithms of elimination of consequences of natural disasters. Each year the direct damage caused by natural disasters is estimated of about 20 million USD dollars (KMES, 2014)

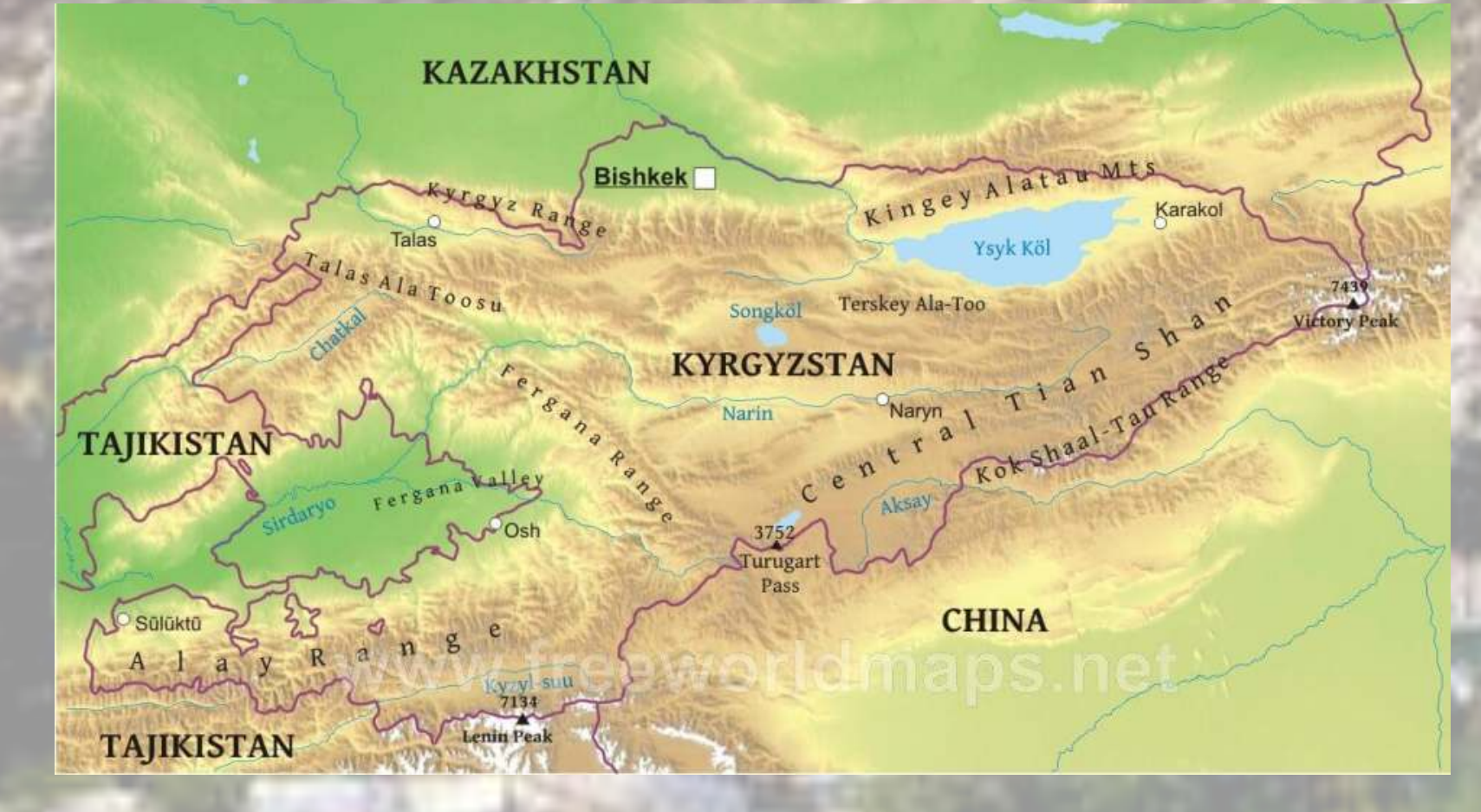

The specific room in a spectrum of emergencies and crises belongs to conflicts within Kyrgyz social system, officially defined as a parliamentary republic. The constant opposition between the North and the South of Kyrgyzstan does not improve the internal political situation, which has been extremely unstable in the last two decades due to the local takeovers (for instance in March 2005 and in April 2010). The most painful crises in KR are associated with interethnic tension, which has been lasting for ages between people living in Fergana Valley.

The last one took place in 2010, and its consequences are visible until now.
The goal of the study was to touch the dynamics of the symptoms of traumatic stress in Osh events survivors, and measure the level of interethnic tension in their children, who now are 16 and older.

\section{Methods}

Repeated measures design was used to assess the level of traumatic stress, dissociative symptoms, and level of interethnic tension in 250 respondents (60 Uzbeks and 190 Kyrgyz survivors) in 2010, 2011 2013,2015 , and 2018. Repeated measures design was used to assess the level of traumatic stress, dissociative and somatic symptoms in 250 survivors diagnosed with PTSD in 2010. A battery of psychological tools, including scales of traumatic stress, dissociation, semantic differential, and survey to determine the preferable addresses for receiving help was used in the research was used repeatedly in 2011 , 2013, 2015, and 2018. 33, 5\% of the sample was lost during the research primarily due to the processes of external migration. In order to measure the level of interethnic tension, the Semantic Differential and Index of Semantic Closeness were used with the concepts "people of my ethnicity" and "people of the other ethnicity"

\section{Results}

The wave-like pattern of the curve of inter-ethnic tension with a relative decline in 2013, a rise in 2015, and a plateau from 2015 and 2018 shows that the conflict is still there.

\section{Index of Semantic Closeness}

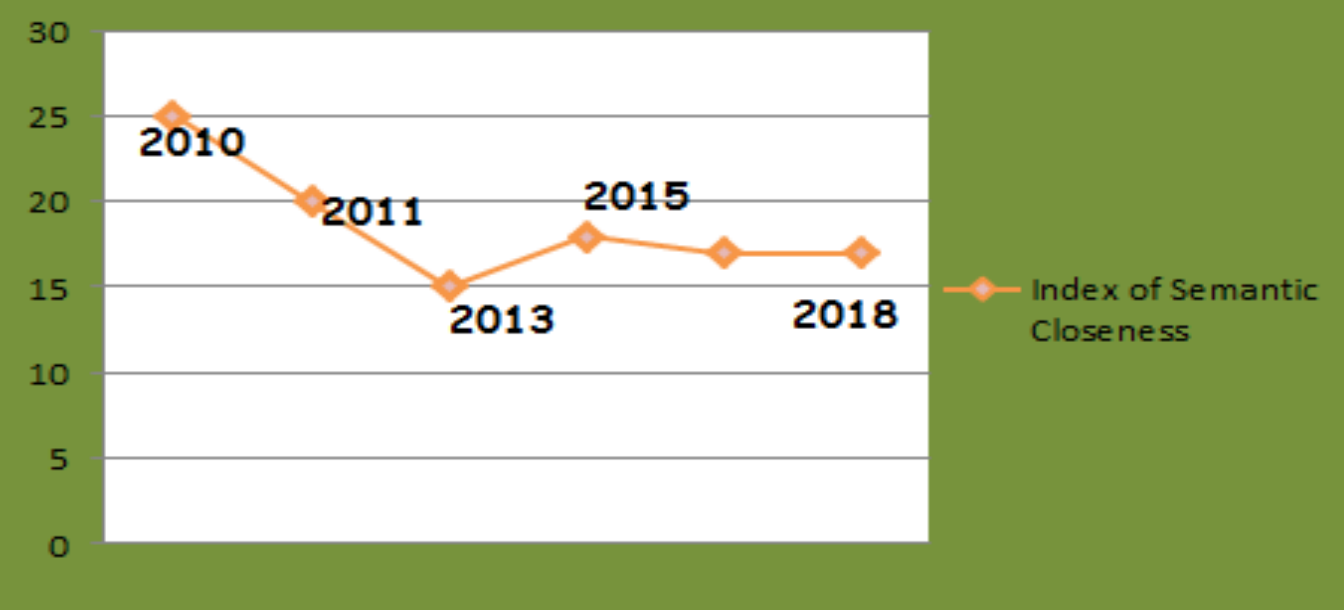

Level of traumatic stress symptoms in women since 2013 negatively correlates with the severity of dissociative symptoms $(r=-0,65 ; p<$ .01).

Children of our initial respondents, showed significantly $(p<0.05)$ higher level of interethnic tension in comparison with the adults.

Osh citizens still prefer to address their problems to traditional healers.

\section{Conclusion}

Dissociative symptoms and somatic symptoms in survivors are connected with the severity of traumatic stress. The new generation children of traumatized Osh citizens demonstrate a higher level of interethnic tension than their parents, which makes this region still vulnerable for interethnic clashes. 